\title{
PENGARUH GAYA KOLONIAL BELANDA PADA INTERIOR RUMAH TINGGAL DI KAYUTANGAN MALANG
}

\author{
Grace Setiati \\ Program Studi Desain Interior, Fakultas Seni dan Desain, Universitas Kristen Petra, \\ Jl. Siwalankerto 121-131, Surabaya \\ Email: gracesika@petra.ac.id
}

\begin{abstract}
Abstrak
Kota Malang disebut sebagai salah satu hasil perencanaan kota kolonial yang terbaik di Hindia Belanda. Pusat Kota Malang pada tahun 1914 terletak di kawasan Kayutangan hingga alun-alun Kota Malang. Kawasan Kayutangan merupakan kawasan perdagangan Kota Malang di masa pendudukan kolonial Belanda. Pengaruh perkembangan arsitektur kolonial Belanda masuk dalam permukiman masyarakat pribumi, termasuk permukiman di Kayutangan. Penelitian ini bertujuan untuk mengkaji pengaruh gaya desain kolonial Belanda pada interior rumah tinggal di kawasan Kayutangan Malang. Metode penelitian menggunakan metode kualitatif yang bersifat deskriptif dengan studi kasus. Hasil penelitian menunjukkan terdapat pengaruh gaya desain kolonial Belanda pada interior rumah tinggal di Kayutangan, dengan adaptasi bahan lokal dan penyesuaian terhadap iklim tropis kota Malang, juga terdapat pengaruh pencampuran budaya Eropa, China dan budaya tradisional masyarakat Jawa. Gaya desain kolonial diwujudkan pada fisik bangunan melalui penyederhanaan bentuk sesuai dengan kemampuan, interpretasi dan teknologi yang dimiliki saat itu dan tetap bertahan hingga kini.
\end{abstract}

Kata kunci: gaya kolonial Belanda, interior, rumah tinggal, Kayutangan, Malang.

\begin{abstract}
Title : The Influence of Dutch Colonial Style on Design Residential in Kayutangan Malang

Malang is referred to as one of the best products of colonial town planning in the Dutch East Indies. The city center of Malang in 1914 is located in the Kayutangan to Malang town square. Region Kayutangan a commercial area of Malang in the Dutch colonial occupation. Influence of development of Dutch colonial architecture included in the settlement of indigenous people, so with Kayutangan. This study aims to assess the legacy of Dutch colonial style design of houses in the area Kayutangan Malang. The research method using descriptive qualitative method with case studies. Research result shows there are significant design style colonial with the adaptation of local materials and adapted to the tropical climate in the city of Malang, there is also a mixing effects of European culture, Chinese traditional culture and the Java community. Colonial design style is manifested in the physical building with simplification of forms, according to ability, interpretation and technologies currently owned and maintained until now.
\end{abstract}

Keywords: Dutch colonial style, interior, residential, Kayutangan, Malang.

\section{Pendahuluan}

Sebagai kota terbesar kedua setelah Surabaya di Jawa Timur, Kota Malang merupakan salah satu hasil perencanaan kota kolonial terbaik di Hindia Belanda (Handinoto, 1996). Pusat Kota Malang pada masa kolonial Belanda pada tahun 1914 terletak di kawasan Kayutangan hingga alun-alun 
kota. Kawasan Kayutangan merupakan kawasan perdagangan di Kota Malang pada masa pendudukan kolonial Belanda. Kawasan ini juga merupakan jalan penghubung antara kota Malang dengan Kota Surabaya, sehingga menjadi daerah yang strategis untuk perdagangan. Kawasan Kayutangan berkembang membentuk pola ruang gerak masyarakat pada area belakang pertokoan. Masyarakat mendirikan rumah tinggal dan membentuk permukiman yang secara tidak langsung mengadopsi karakter arsitektur kolonial Belanda (Karisztia, Pangarsa, \& Antariksa, 2008). Warga setempat menempati kawasan perkampungan kota yang terletak di dalam gang-gang Kayutangan.

Dalam perkembangannya, deretan bangunan kolonial Belanda masih banyak ditemukan di antara gang-gang kecil seluas setengah meter hingga dua meter, dengan sejarah penghuni adalah warga pribumi dari awal berdirinya bangunan hingga saat dilakukan penelitian. Sejarah penghuni warga setempat ini diperkuat dengan adanya makam keramat Mbah Honggo Koesoemo di salah satu area permukiman Kayutangan. Menurut Heriyanto, juru kunci makam, Mbah Honggo merupakan warga Kerajaan Mataram dan juga pengikut Pangeran Diponegoro. Mbah Honggo menjadi buronan Belanda, karena membantu perjuangan Pangeran Diponegoro. Mbah Honggo kemudian melarikan diri dan menetap di kawasan Kayutangan. Mbah Honggo berperan membuka Pasar Talun dan mengubah area yang dulunya merupakan hutan menjadi permukiman di belakang pertokoan Kayutangan. Hingga akhir hayatnya, keturunan Mbah Honggo dipercaya masih menetap di kawasan tersebut.
Ciri fisik permukiman Kayutangan antara lain didirikan di lahan terbatas, sebagian besar tidak memiliki halaman di sekitar rumah, bagian samping atau belakang rumah menempel dengan rumah tetangga, ruang yang tidak luas, sirkulasi atau gang yang sempit, serta bangunan yang mengadopsi gaya kolonial Belanda.

Penelitian ini bertujuan untuk mengidentifikasi, menganalisis dan mendeskripsikan gaya desain kolonial Belanda pada rumah tinggal di Kayutangan Malang. Pemilihan lokasi objek penelitian diambil dari beberapa kasus bangunan yang terletak di Kayutangan J1. Basuki Rahmat Gang 2 s/d Gang 8 Malang. Alasan pemilihan lokasi karena permukiman di Kayutangan merupakan salah satu kawasan permukiman di Kota Malang pada pemerintahan Belanda di mana masih banyak ditemukan rumah bergaya kolonial. Fokus penelitian dibatasi pada studi gaya desain kolonial Belanda pada desain rumah tinggal di Kayutangan, karena sebelumnya telah dilakukan penelitian oleh peneliti lain yang berkaitan dengan lingkup arsitektur. Dengan demikian, penelitian ini merupakan penelitian lanjutan yang membatasi studinya pada lingkup desain interior.

\section{Metode Penelitian}

Penelitian ini menggunakan metode kualitatif, yang digunakan untuk mengeksplorasi dan memahami makna yang berasal dari masalah sosial ataupun kemanusiaan (Creswell, 2012). Penelitian ini merupakan jenis penelitian kualitatif deskriptif dengan studi kasus. Pengumpulan data penelitian ini dilakukan dengan 
Tabel 1. Pengelompokan jenis dan fungsi rumah tinggal

\begin{tabular}{|c|c|c|c|}
\hline No & Rumah & Tahun Berdiri & Pengelompokan Jenis dan Fungsi Rumah Tinggal \\
\hline 1. & $\begin{array}{l}\text { Ibu Tutik Jl. Basuki } \\
\text { Rahmat Gg. IV No. } 1 \\
\text { (IT) }\end{array}$ & 1930-an & $\begin{array}{l}\text { Merupakan rumah tinggal yang bentuk fisik } \\
\text { bangunan tetap dipertahankan seperti awal bangunan } \\
\text { berdiri. }\end{array}$ \\
\hline 2. & $\begin{array}{l}\text { Ibu Fitria Jl. Basuki } \\
\text { Rahmat Gg. IV No. } \\
938 \text { (IF) }\end{array}$ & 1923 & $\begin{array}{l}\text { Merupakan rumah tinggal dengan ciri dan warna } \\
\text { atraktif, didominasi warna peach dan hijau pada } \\
\text { fasad bangunan. }\end{array}$ \\
\hline 3. & $\begin{array}{l}\text { Ibu Anik Jl. Basuki } \\
\text { Rahmat Gg. VI No. } \\
962 \text { (IA) }\end{array}$ & 1930-an & $\begin{array}{l}\text { Merupakan rumah huni usaha. Selain sebagai rumah } \\
\text { tinggal juga menjadi tempat usaha berjualan pangsit } \\
\text { mie dengan pangsa pasar masyarakat sekitar. } \\
\text { Penggabungan fungsi rumah tinggal dan usaha } \\
\text { berpengaruh terhadap sifat ruang dan zoning } \\
\text { ruangnya. }\end{array}$ \\
\hline 4. & $\begin{array}{l}\text { Bapak Aji Jl. Basuki } \\
\text { Rahmat Gg. II A No. } \\
505 \text { (BA) }\end{array}$ & 1930-an & $\begin{array}{l}\text { Merupakan rumah huni usaha untuk mengoleksi dan } \\
\text { menjual barang antik. Fungsi ruang tidur utama } \\
\text { berubah menjadi tempat penyimpanan barang antik. } \\
\text { Perubahan zoning mengakibatkan perubahan sifat } \\
\text { ruang. }\end{array}$ \\
\hline 5. & $\begin{array}{l}\text { Bapak Suryadi Jl. } \\
\text { Basuki Rahmat Gg. IV } \\
\text { No. } 835 \text { (BS) }\end{array}$ & 1920-an & $\begin{array}{l}\text { Merupakan rumah tinggal yang mengalami } \\
\text { perubahan fungsi dan penambahan ruang, sehingga } \\
\text { berpengaruh pada zoning dan sifat ruangnya. Teras } \\
\text { samping diubah fungsinya menjadi ruang tidur } \\
\text { sehingga pola aktifitas ruang berubah. }\end{array}$ \\
\hline 6. & $\begin{array}{l}\text { Ibu Ida Jl. Arief } \\
\text { Rahman Hakim Gg. } \\
\text { IIB No. } 1218 \text { (II) }\end{array}$ & 1920-an & $\begin{array}{l}\text { Rumah peninggalan keluarga yang kosong } \\
\text { dimanfaatkanmenjadi rumah kost untuk mahasiswa } \\
\text { putra. Perubahan fungsi rumah tinggal berpengaruh } \\
\text { pada zoning dan aktifitas yang terjadi. }\end{array}$ \\
\hline
\end{tabular}

Sumber: Analisis Penulis, 2015

observasi langsung terhadap obyek penelitian yaitu melakukan pengamatan terhadap fasad bangunan, lay out, organisasi ruang, elemen pembentuk ruang, elemen transisi interior dan elemen pendukung ruang (perabot). Metode deskriptif digunakan untuk untuk menjelaskan hasil dan pembahasan gaya kolonial Belanda pada desain rumah tinggal di kawasan Kayutangan, Malang.

\section{Hasil dan Pembahasan}

Data Fisik Rumah-rumah di Kayutangan yang Menjadi Obyek Penelitian

Penelitian ini mengambil kasus enam rumah tinggal yang dapat dikelompokkan berdasarkan jenis dan fungsi rumahnya dan memiliki ciri-ciri tertentu (Tabel 1).

Dari Tabel 1 dapat disimpulkan bahwa rumah tinggal yang menjadi kasus penelitian dapat dikelompokkan menjadi tiga jenis yaitu rumah tinggal, rumah huni usaha dan rumah kost. Terdapat tiga rumah tinggal, dua rumah huni usaha dan satu rumah kost khusus mahasiswa putra. Rumah tinggal berfungsi secara umum sebagai tempat aktivitas rumah tangga. Pada rumah huni usaha terjadi penggabungan aktivitas rumah tangga dan usaha menjadi satu, sehingga berpengaruh pada zoning dan sifat ruang. Terjadi benturan fungsi dan penumpukan aktivitas dalam satu ruang yaitu ruang tamu sekaligus berfungsi sebagai ruang makan untuk warung karena keterbatasan area. 
Demikian pula perubahan rumah tinggal menjadi rumah kost berpengaruh terhadap zoning dan aktifitasnya. Zona publik lebih mendominasi karena digunakan secara bersama-sama seperti ruang tamu, ruang makan dan kamar mandi.

\section{Analisis Fasad Bangunan}

Bentuk arsitektural dari 6 (enam) kasus rumah tinggal di Kayutangan Malang dilihat dari komposisi fasad bangunan, memiliki dua tipe. Agar memudahkan pembagian, nama tiap rumah disingkat sesuai dengan nama pemilik rumah, yaitu: Ibu Tutik (IT), Ibu Fitria(IF), Bapak Suryadi (BS), Ibu Anik (IA), Bapak Aji (BA), dan Ibu Ida (II).
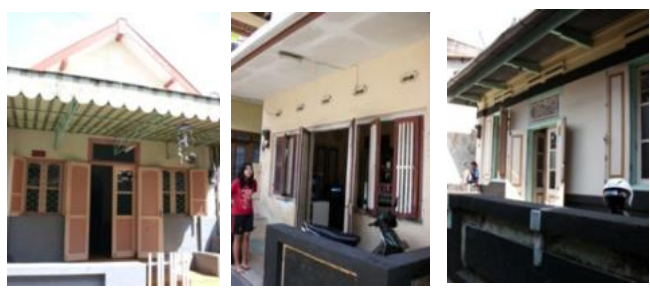

Gambar 1. Tipe fasad simetris rumah IF, IA dan BA

Sumber: Dokumentasi Penulis, 2015

Tipe fasad bangunan dibagi dua sebagai berikut. Tipe 1 (Gambar 1): Fasad simetris pada tiga kasus Rumah IF, IA dan BA) merupakan ciri dari Indische Empire yang masih banyak diterapkan pada masa transisi atau peralihan kolonial Belanda (18901915). Fasad simetris merupakan ciri khas dari arsitektur bangunan kolonial Belanda pada tahun 1800-1900an (Handinoto, 2010). Pencapaian masuk bangunan melalui area tengah bangunan yaitu pintu rangkap ganda, yang diapit jendela ganda di sisi kiri dan kanan bangunan. Pada tiga kasus yang diteliti tidak ditemukan kolomkolom doric atau ionic yang menjadi ciri façade simetris, karena pada masa peralihan (1890-1915) pemakaian kolom sudah jarang digunakan
(Handinoto, 2010). Selain itu juga karena lahan dan teknologi yang dimiliki terbatas, disesuaikan dengan kondisi setempat.
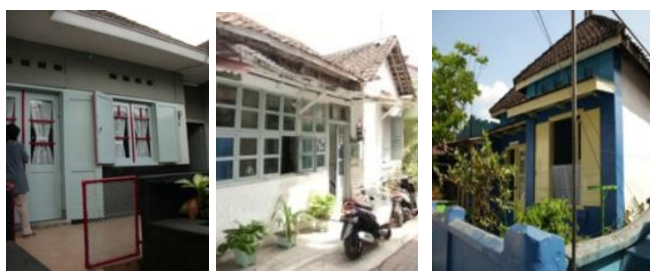

Gambar 2. Tipe fasad asimetris rumah II, IT dan BS

Sumber: Dokumentasi Penulis, 2015

Tipe 2 (Gambar 2): Fasad asimetris pada tiga kasus (Rumah II, IT dan BS) lebih mengutamakan segi fungsional. Façade asimetris merupakan ciri dari arsitektur kolonial modern (19151940) yang juga berkembang di permukiman Kayutangan (Handinoto, 2010). Ciri dari fasad asimetris ini adalah posisi pintu terletak di samping kiri atau kanan bangunan, dan dilengkapi dengan jendela yang disesuaikan dengan fungsi, bahan, teknologi dan iklim setempat. Adanya sun shading pada bagian tampak muka atau fasad rumah merupakan pengaruh dari arsitektur kolonial modern sebagai pengganti dari teras keliling bangunan yang banyak dijumpai pada masa Indische Empire. Sunshading merupakan penyesuaian dengan iklim tropis basah, agar sinar matahari dan hujan tidak mengenai rumah secara langsung.

Teras pada rumah tinggal Kayutangan dilengkapi dengan pagar pembatas atau balustrade yang menjadi ciri khas bangunan kolonial di Kayutangan merupakan pengaruh dari arsitektur Eropa (Gambar 3). Ciri dari balustrade di rumah tinggal Kayutangan Malang dibuat dari beton cor dengan finishing cat tembok dan batu tabur warna hitam. Pada umumnya balustrade pada 
bangunan kolonial memiliki detail ragam hias, namun balustrade pada rumah tinggal di Kayutangan mengalami penyederhanaan bentuk dengan menggunakan bahan lokal.

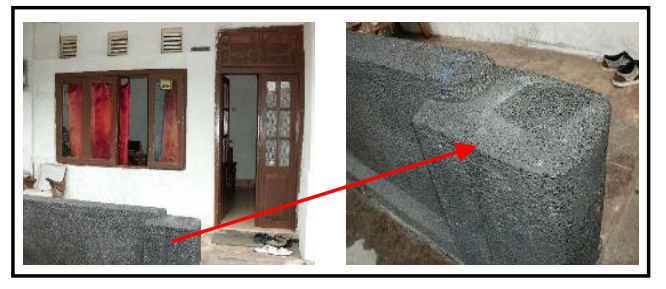

Gambar 3. Balustrade dari beton cor

Sumber: Dokumentasi Penulis, 2015

Berdasarkan analisis di atas, dapat ditarik simpulan keseluruhan kasus bangunan rumah tinggal di Kayutangan menerapkan gaya desain kolonial Belanda pada fasad bangunan. Hal ini terlihat dari penggunaan fasad simetris dan asimetris yang merupakan pengaruh Indische Empire dan era kolonial modern. Sebagian besar kasus memiliki sunshading dan balustrade yang merupakan pengaruh gaya kolonial dan adaptasi dari iklim tropis basah. Ciri lain adalah adanya penyederhanaan bentuk karena teknologi dan bahan yang dimiliki masa itu terbatas, selain karena lahan yang terbatas.

\section{Analisis Lay Out Bangunan}

Pola lay out simetris pada enam kasus rumah tinggal di Kayutangan jika dilihat secara global maupun berdasarkan pola ruang keseluruhan bangunan, tidak ada yang memiliki pola simetris penuh, seperti halnya ciri khas bangunan kolonial pada umumnya, khususnya pada era 'Indische Empire' (Handinoto, 2010). Berdasarkan tahun berdirinya (antara tahun 1920-1940), lay out ke enam kasus rumah tinggal di Kayutangan secara keseluruhan tidak simetris, hal ini sesuai dengan era yang berkembang saat itu yaitu masa arsitektur kolonial modern (1920-1940). Penentuan pola lay out bukan karena pertimbangan faktor simetris, tapi lebih kepada kebutuhan penghuni terhadap ruangruang.

Pada kasus rumah IF terdapat pagar keliling yang membatasi dengan rumah lainnya, merupakan pengaruh dari masa Arsitektur Transisi (1890-1915). Pada kasus rumah IF dan II terdapat pintu samping bangunan yang memiliki gang kecil untuk menghubungkan secara langsung area publik dengan area servis dan area privat. Seperti halnya beranda yang banyak diterapkan di jaman "Indische Empire", adanya gang kecil di samping rumah merupakan penyesuaian dengan iklim tropis lembab, sebagai cross ventilation yang baik.

Ditemukan kasus Rumah Kopel pada rumah II. Rumah Kopel merupakan dua rumah di mana dindingnya saling menyatu satu dengan yang lain sebagai upaya menghemat biaya (Handinoto 2010). Rumah II yang beralih fungsi menjadi rumah kost dindingnya menyatu dengan rumah tinggal sebelah. Rumah Kopel banyak ditemukan di Kayutangan karena lebih menghemat biaya dan sesuai dengan lingkungan Kayutangan yang lahannya terbatas.

Berdasarkan bentuk lay out dan pola penataannya, ke enam kasus rumah mendapatkan pengaruh gaya desain kolonial Belanda yang berkembang pada periode setelah tahun 1900-an yaitu bangunan berbentuk ramping dan memanjang untuk memudahkan cross ventilation dan pertukaran udara dalam ruang. Hal tersebut merupakan penyesuaian bangunan dengan iklim tropis basah. 


\section{Analisis Organisasi Ruang}

5 (lima) kasus rumah memiliki organisasi linier dengan sirkulasi linier bercabang. Hal ini merupakan ciri dari bangunan kolonial Belanda. Ciri organisasi ruang pada rumah Landhuizen (bangunan rumah tinggal kolonial Belanda) adalah kecenderungan bentukan lay out yang sempit dan memanjang ke belakang, sehingga membentuk sistem organisasi ruang yang linier.

Organisasi ruang di 5 (lima) kasus rumah terdiri dari tiga tipe organisasi : pertama organisasi linier, sirkulasi bercabang dengan gang penghubung sebagai penghubung ruang, kedua organisasi linier dengan sirkulasi bercabang simetris, memisahkan ruang-ruang di kiri-kanannya menjadi dua kawasan yang berbeda dan ketiga adalah organisasi klaster. Terdapat satu kasus rumah yang memiliki organisasi klaster akibat perubahan ruang berupa penambahan ruang-ruang di area samping kiri depan bangunan. Organisasi klaster fleksibel dan dapat menerima pertumbuhan dan perubahan langsung tanpa memengaruhi karakternya. Sirkulasi klaster mengikuti pola ruang yang terbentuk.

\section{Analisis Elemen Pembentuk Ruang pada Lantai}
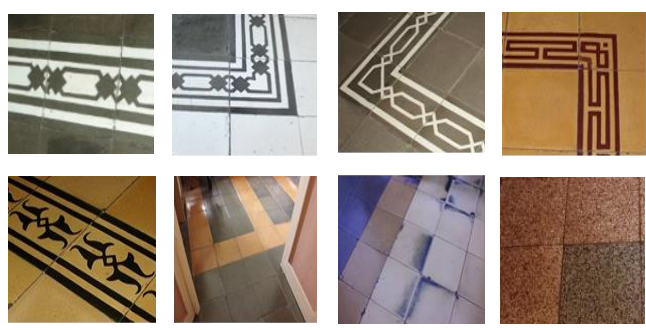

Gambar 4. Pola border lantai

Sumber: Dokumentasi Penulis, 2015

Elemen pembentuk ruang terdiri dari lantai, dinding dan plafon. Enam kasus rumah tinggal di Kayutangan menggunakan lantai teraso berukuran $20 \times 20 \mathrm{~cm}$ yang merupakan material jaman kolonial dan adaptasi dari iklim tropis. Kelebihan dari teraso adalah mampu menyerap panas, sehingga ruang cenderung lebih dingin, kedap air dan keras, sehingga dapat mengatur temperatur dan kelembaban udara di dalam ruangan.

Berdasarkan pola lantai, keenam kasus memiliki border lantai menyesuaikan dengan bentuk ruang dan dibagi menjadi 3 tipe pola border lantai (Gambar 4): pola geometris garis dan persegi, pola organik dan non motif. Ditemukan pengaruh motif Yunani dan Eropa Edwardian (1901-1914) (Calloway, 1991) pada ornamen hias di dua rumah tinggal yang diteliti (Gambar 5).

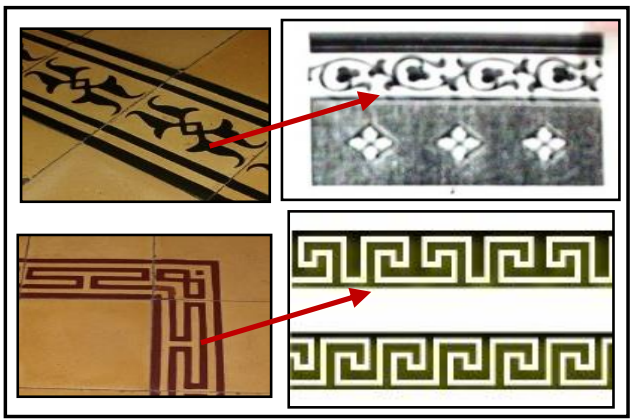

Gambar 5. Pengaruh motif Yunani dan Eropa

Sumber: Dokumentasi Penulis, 2015

\section{Analisis Elemen Pembentuk Ruang pada Dinding}

Penyesuaian dan adaptasi dengan lingkungan setempat pada material dinding terlihat dari penggunaan anyaman bambu (gedheg) pada dinding salah satu kasus yaitu rumah tinggal IT (Gambar 6). Anyaman bambu merupakan budaya tradisional Jawa dan memiliki karakter yang unik. Bambu dikenal memiliki kekokohan yang tinggi sebagai konstruksi sekunder atau sebagai anyaman (Frick, 1997). 


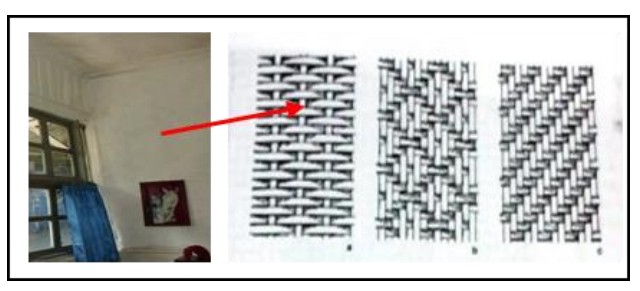

Gambar 6. Pengaruh budaya tradisional Jawa pada dinding rumah tinggal IT Sumber: Dokumentasi Penulis, 2015

Lima kasus rumah menggunakan dinding batu bata tebal dengan finishing plesteran yang pada mulanya rata-rata berwarna putih, tetapi dalam perkembangannya warna dinding berubah menjadi warna hijau muda, biru muda, abu-abu dan krem sesuai dengan keinginan pengguna dan perkembangan jaman. Dinding rumah dengan ketebalan $30 \mathrm{~cm}$ (Gambar 7), seperti klinker yang merupakan batu bata tebal adaptasi dari bentukan struktur kolonial menggunakan bahan lokal yaitu batu bata (Samsudi, 2000). Ketebalan dinding pada rumah mengakibatkan peresapan panas ke dalam rumah lebih terhambat.

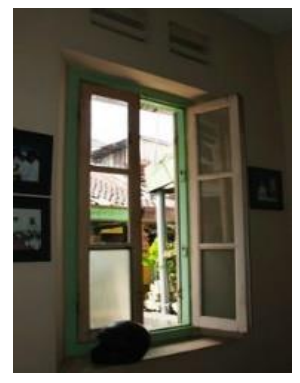

Gambar 7. Pengaruh gaya kolonial pada dinding batu batal tebal (klinker)

Sumber: Dokumentasi Penulis, 2015

Detail ornamen pada dinding yang merupakan ciri Empire Style tidak ditemukan pada rumah-rumah tersebut. Hal ini bisa jadi merupakan penyederhanaan bentuk karena interpretasi dan penyederhanaan teknologi yang dimiliki.

\section{Analisis Elemen Pembentuk Ruang pada Plafon}

Pada bagian plafon terdapat pengaruh budaya tradisional Jawa di mana plafon menggunakan material anyaman bambu (gedheg) di tiga kasus rumah (Gambar 8). Material bambu memiliki sifat kokoh yang tinggi, sehingga tetap dipertahankan hingga sekarang (Frick, 1997). Penggunaan anyaman bambu ini juga menjadi ciri khas rumah tinggal kolonial di Kayutangan.

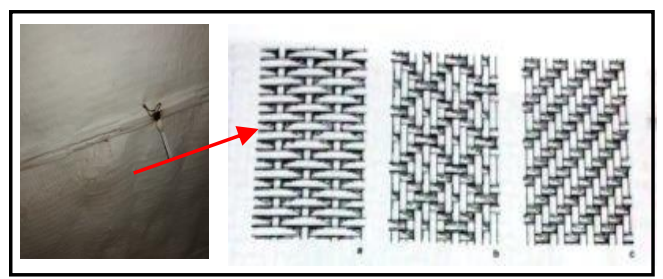

Gambar 8. Pengaruh budaya tradisional Jawa pada plafon

Sumber: Dokumentasi Penulis, 2015

Tiga kasus rumah yang lain menggunakan bahan eternit dan tripleks dengan pola ornamen grid finishing cat putih (Gambar 9). Semua kasus memiliki ketinggian plafon 3 meter. Plafon tinggi mengakibatkan udara panas dari atap tidak langsung mengenai perabot di dalam rumah. Hal ini merupakan penyesuaian dari iklim tropis yang ada di Malang.

Bidang datar yang merupakan ciri dari rumah kolonial Belanda diterapkan juga di rumah tinggal bergaya kolonial di Kayutangan, dengan permukaan datar dan berwarna putih.

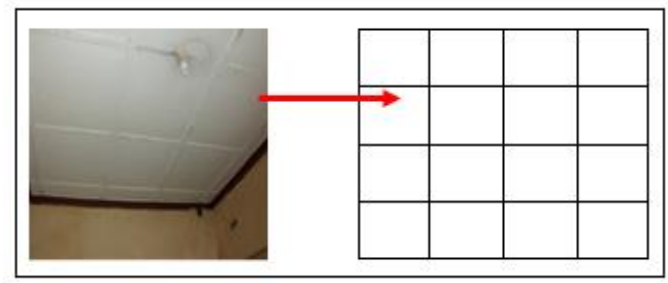

Gambar 9. Pola grid plafon rumah IF, IA dan BA

Sumber: Dokumentasi Penulis, 2015 


\section{Analisis Elemen Transisi Pintu}

Pintu di rumah tinggal Kayutangan merupakan pintu bergaya kolonial dengan ciri memiliki dua bukaan dan berpanel motif geometris. Selain itu juga menggunakan bahan kayu jati yang merupakan adaptasi dari budaya setempat. Pada salah satu rumah ditemukan adanya kaca dekoratif pada pintu masuk dari bahan kaca patri atau stained glass bergaya Art Nouveau (Gambar 10).

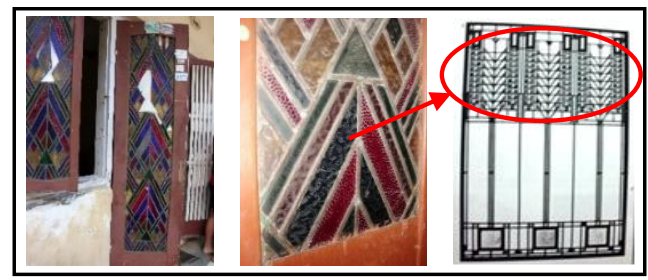

Gambar 10. Pengaruh motif Art Nouveau pada pintu

Sumber: Dokumentasi Penulis, 2015

Berdasarkan jenisnya, terdapat 3 jenis pintu yaitu pintu rangkap ganda, pintu ganda dan pintu tunggal. 3 tipe rumah menggunakan pintu rangkap ganda, lapis luar kayu masif detail geometris, lapisan dalam kayu dan kaca bening atau warna. 3 tipe rumah lain menggunakan pintu ganda bahan kayu dan kaca bening serta kaca patri atau stained glass. Terdapat juga pintu tunggal berupa pintu geser, dengan bahan kayu jati dan kaca patri atau stained glass.

\section{Analisis Elemen Transisi Jendela}

Terdapat 3 jenis jendela pada rumah tinggal di Kayutangan yaitu jendela rangkap ganda, jendela ganda dan jendela tunggal. Penggunaan kayu jati sebagai bahan lokal banyak digunakan pada masa kolonial, demikian halnya pada kasus di rumah tinggal Kayutangan. Pengaruh kolonial, tradisional Jawa dan iklim setempat (tropis) tampak terlihat pada penggunaan elemen pintu berbentuk panel geometris dan bahan kayu jati. Adanya bukaan yang lebar mengakibatkan ruang-ruang mendapat pencahayaan dan penghawaan alami yang baik. Ditemukan pula kaca dekoratif pada jendela dari bahan kaca patri atau stained glass jaman Art Nouveau (Gambar 11). Gaya Art Nouveau merupakan salah satu gaya yang mempengaruhi arsitektur bangunan kolonial Belanda.

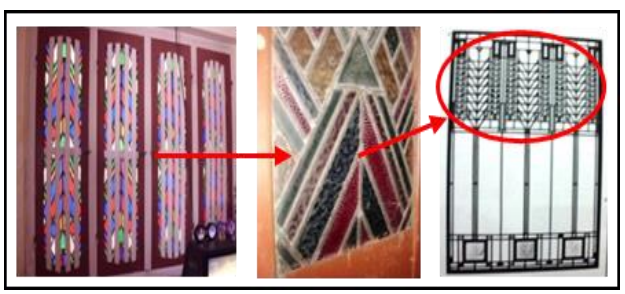

Gambar 11. Pengaruh motif Art Nouveau pada jendela

Sumber: Dokumentasi Penulis, 2015

\section{Analisis Elemen Transisi Ventilasi}

Ventilasi dibagi menjadi 2 tipe, tipe lubang angin atau kisi-kisi dan bouvenlight. Tipe 1: lubang angin berbentuk persegi dengan motif geometris. Tipe 2: bouvenlight polos tanpa ornamen, hanya kayu jati dan kaca serta bouvenlight dengan teralis motif geometris. Pada tiga kasus rumah ditemukan bouvenlight di atas pintu yang memiliki pola geometric lattice, yang merupakan pola dari kebudayaan China (http://www.stencillibrary.co.uk/chinesestyle-budgetstencils/page1.html, diakses pada 2 Agustus 2015) (Gambar 12).

Tidak diketahui secara pasti asal muasal digunakannya pola tersebut pada ventilasi rumah, mengingat pemilik dan penghuni dari awal bangunan dibangun adalah warga setempat. Bisa jadi merupakan interpretasi pemilik dalam mengadopsi bangunan kolonial yang di lihat di pemukiman pusat kota pada masa itu. Bahan kisi-kisi adalah besi tempa dan 
semen. Bouvenlicht menggunakan besi tempa, kayu jati dan kaca es.

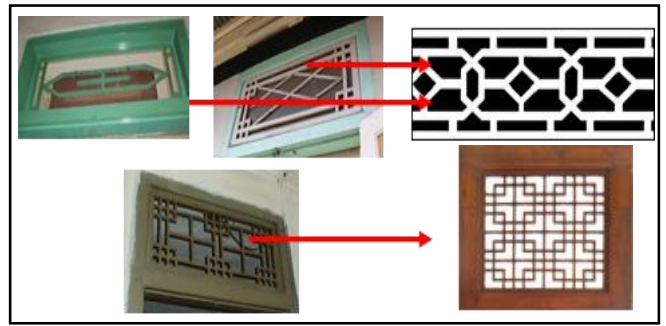

Gambar 12. Pengaruh geometric lattice budaya China pada bouvenlight

Sumber: Dokumentasi Penulis, 2015

\section{Analisis Perabot}

Perabot jarang ditemukan di 6 (enam) kasus rumah tinggal yang diteliti. Hanya tertinggal beberapa peninggalan kursi dan meja yang dapat dianalisis gaya desainnya. Ditemukan kursi makan pada kasus rumah tinggal di Kayutangan bergaya kolonial Belanda, merupakan perwujudan bentuk dari gaya kolonial (Gambar 13).

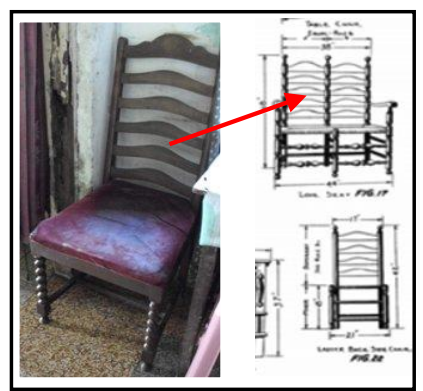

Gambar 13.Pengaruh gaya mebel kolonial pada kursi makan

Sumber: Gottshall, 1989

Ditemukan juga kursi bergaya "Majapahitan" yang banyak di produksi pada masa kolonial, dengan ciri berbahan kayu jati dan anyaman rotan (Gambar 14). Pada bagian samping kursi terdapat ragam hias corak Majapahit yang merupakan paduan ragam hias Hindu, Mataram dan Yogya (Septi dan Sachari, 2007).

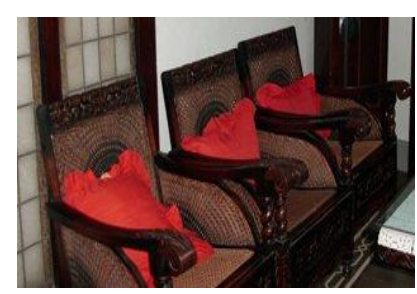

Gambar 14. Pengaruh gaya Majapahitan pada kursi

Sumber: Dokumentasi Penulis, 2015

Terdapat pula meja yang merupakan adaptasi dari gaya Queen Anne dengan ciri khas ukiran pilin (twisted) seperti kursi Mollucan yang berkembang di Eropa (Gambar 15).

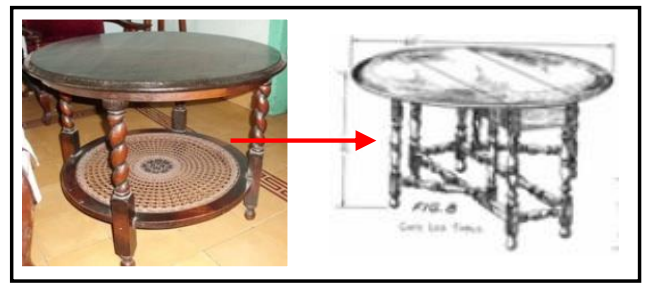

Gambar 15. Pengaruh gaya Queen Anne pada meja

Sumber: Gottshall, 1989

Selain itu ditemukan kursi santai dengan pengaruh gaya Perancis (Gambar 16). Gaya Perancis pada prinsipnya memiliki karakter bentuk mebel yang lembut dan luwes (Septi dan Sachari, 2007). Bahan yang digunakan kursi santai ini adalah bahan lokal kayu jati dipadukan dengan anyaman rotan.

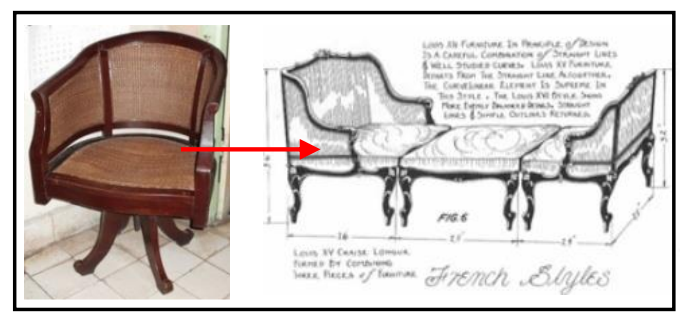

Gambar 16. Pengaruh gaya Perancis pada kursi santai

Sumber: Gottshall, 1989 


\section{Kesimpulan}

Hasil analisis menunjukkan bahwa terdapat pengaruh gaya desain kolonial Belanda pada desain rumah tinggal di Kayutangan yang diteliti. Terdapat pula pengaruh pencampuran budaya Eropa, China dengan budaya tradisional masyarakat Jawa serta adaptasi dengan iklim tropis di Kota Malang. Dari hasil analisis ke enam kasus rumah tinggal yang diteliti merupakan bangunan kolonial yang dibangun pada era Arsitektur Peralihan (1890-1915) dan Arsitektur Kolonial Modern (1915-1940). Gaya desain kolonial diwujudkan pada fisik bangunan dengan penyederhanaan bentuk sesuai dengan kemampuan, interpretasi dan teknologi yang dimiliki saat itu, sehingga karakter bentuk rumah tinggal serta interior yang ada di dalam gang-gang di Kayutangan lebih kuat unsur lokalnya dibandingkan dengan kota lain. Selain itu juga karena keterbatasan lahan yang ada di kawasan Kayutangan, perwujudan gaya desain kolonial lebih terbatas.

Unsur lokal dipengaruh budaya masyarakat Jawa yang diaplikasikan pada sebagian besar material bangunan dan interior, antara lain anyaman bambu pada dinding dan plafon, anyaman rotan dan kayu jati pada perabot. Penyesuaian dengan iklim tropis diterapkan dengan menyediakan banyak bukaan baik jendela maupun ventilasi, teras dan pintu samping. Ditemukan juga pengaruh budaya China pada motif teralis bouvenlicht di beberapa rumah, hal ini dikarenakan penduduk setempat mengadopsi karakter bangunan yang dilihat di pusat kota dan menerapkannya pada rumah tinggal mereka. Terdapat pula pengaruh budaya Yunani dan Art
Nouveau pada ragam hias lantainya dan kaca patri, serta adopsi gaya Eropa pada mebel menggunakan bahan lokal.

Pencampuran dari beberapa gaya dan budaya serta penyesuaian dengan iklim tropis pada bangunan kolonial terbukti menjadi warisan arsitektural bangsa yang teruji dan tetap bertahan hingga saat ini. Namun sayang saat ini banyak bangunan kolonial yang mulai rusak, tidak dipelihara dengan baik, dipugar atau diganti menjadi bangunan baru karena masyarakat lebih memilih trend arsitektur modern yang berkembang. Padahal bila dicermati, trend tersebut tidak selamanya cocok dengan lingkungan dan iklim di Indonesia. Demikian halnya dengan bangunan di kawasan Kayutangan yang keberadaannya memberikan citra kolonial mulai rusak dan terlupakan karena perubahan nama jalan menjadi Jalan Jenderal Basuki Rahmat. Bangunan yang terdapat di Kawasan Kayutangan baik itu yang di area jalan maupun di dalam gang-gang kota hendaknya tetap dilestarikan dan dipertahankan sebagai identitas desain Indonesia yang khas sehingga tidak hilang di kemudian hari.

\section{Ucapan Terima Kasih}

Peneliti mengucapkan terima kasih kepada Dr. Laksmi Kusuma Wardhani, S.Sn, M.Ds atas dukungan dan masukannya.

\section{Daftar Pustaka}

Creswell, J. W. (2012). Research design :pendekatan kualitatif, kuantitatif dan mixed. Yogyakarta: Pustaka Pelajar.

Calloway, S.(1991).The element of style: an encyclopedia of 
domestic architecture detail.

London: Reed International

Books Ltd.

Frick, H. (1997). Seri strategi arsitektur 1: pola struktural dan teknik bangunan di Indonesia. Yogyakarta: Penerbit Kanisius.

Gottshall, F. (1989). Period furniture. New York: Bonanza Books.

Handinoto. (2010). Arsitektur dan kota-kota di Jawa pada masa kolonial. Yogyakarta: Graha Ilmu.

Handinoto, Soehargo, Paulus H. (1996). Perkembangan kota dan arsitektur kolonial Belanda di Malang. Yogyakarta: Penerbit Andi dan Universitas Kristen Petra Surabaya.

Karisztia, Pangarsa, Antariksa. (2008). Tipologi façade rumah tinggal colonial Belanda di Kayutangan Malang. Arsitektur e-Journal 1 No. 2.

Samsudi. (2000). Aspek-aspek arsitekur colonial Belanda pada bangunan Puri mangkunegaran. Semarang: Program Pasca Sarjana Magister Teknik Arsitektur Undip Semarang.

Septi, I., Sachari, A. (2007). Pergeseran gaya elastic mebel di Keraton Ngayogyakarta Hadiningrat. Tidak dipublikasikan. Yogyakarta: Jurusan Kriya ISI Yogya. 